УДК 621.313 .33

\author{
В.В. Шапошников ${ }^{1,2}$, Р.О. Токарев ${ }^{1,2}$, \\ А.Д. Коротаев ${ }^{1}$, Е.А. Чабанов ${ }^{1,3}$ \\ ${ }^{1}$ Пермский национальный исследовательский политехнический университет, \\ Пермь, Россия \\ ${ }^{2}$ ООО «ИОЛЛА», Пермь, Россия \\ ${ }^{3}$ Волжский государственный университет водного транспорта \\ (Пермский филиал), Пермь, Россия

\section{РАСЧЕТ ТЯГОВОГО УСИЛИЯ ЦИЛИНДРИЧЕСКОГО ЛИНЕЙНОГО ВЕНТИЛЬНОГО ДВИГАТЕЛЯ ДЛЯ ПРИВОДА ПЛУНЖЕРНОГО НАСОСА}

\begin{abstract}
В настоящее время цилиндрические линейные вентильные двигатели используются повсеместно. Их применяют в электроприводах возвратно-поступательного движения различных общепромышленных механизмов, в том числе в глубинных плунжерных насосах. Применение штанговых глубинных насосов менее рентабельно по сравнению с другими способами добычи нефти. Эксплуатация таких агрегатов сопровождается большими фринансовыми затратами. Применение же насосов подобной конструкции на низкодебитных скважинах становится совсем невыгодным с экономической точки зрения.Такие скважины перестают использовать. В настоящее время в Российской Федерации огромное количество низкодебитных скважин не эксплуатируется. Применение штанговых глубинных насосов также обладает дополнительным недостатком в них возникает износ насосно-компрессорных труб и штанг. Большие масса и габариты станковкачалок затрудняют их транспортировку. Именно по этой причине возникает необходимость проведения исследований с целью получения новых технических решений. Исследования подтвердили рентабельность применения глубинных насосов плунжерного типа. Приводом таких насосных агрегатов может быть цилиндрический линейный асинхронный двигатель или цилиндрический линейный вентильный двигатель. Использование данного двигателя возможно при известном тяговом усилии. Оно рассчитывается в настоящей статье. Расчет производится по упрощённой модели цилиндрического линейного вентильного двигателя в декартовой системе координат. Эта модель получена с помощью введения некоторых допущений. Исследованы устройство и принцип действия цилиндрического линейного вентильного двигателя. По полученным расчётным данным были построены зависимости тягового усилияи полезной мощности от действующего значения тока обмотки индуктора. Полезная мощность определялась в диапазоне сверхнизких частот от 1 до 7 Гц. Полученные результаты исследований были проанализированы и даны рекомендации по использованию цилиндрического линейного вентильного двигателя.
\end{abstract}

Ключевые слова: цилиндрический линейный вентильный двигатель, тяговое усилие, сверхнизкая частота, постоянные магниты, полюсное деление, вторичный элемент. 


\author{
V.V. Shaposhnikov ${ }^{1,2}$, R.O. Tokarev ${ }^{1,2}$, \\ A.D. Korotaev', E.A. Chabanov ${ }^{1,3}$ \\ ${ }^{1}$ Perm National Research Polytechnic University, Perm, Russian Federation \\ ${ }^{2}$ LLC "IOLLA", Perm, Russian Federation \\ ${ }^{3}$ Volga State University of Water Transport (Perm branch), \\ Perm, Russian Federation
}

\title{
CALCULATION OF TRACTION FORCE OF A CYLINDRICAL LINEAR BRUSHLESS ENGINE FOR DRIVING A PLUNGER PUMP
}

\begin{abstract}
Currently, cylindrical linear valve motors are used universally. They are used in electric drives of reciprocating electric drives of various general industrial mechanisms, including deep plunger pumps.The use of sucker rod pumps is less cost effective than other methods of oil production. The operation of such units is accompanied by high financial costs. The use of pumps of a similar design in low-rate wells becomes completely unprofitable from an economic point of view.Such wells are no longer used.Currently, in the Russian Federation a huge number of low-yield wells are not in operation. The use of sucker rod pumps also have an additional drawback - they cause wear of tubing and rods. The large mass and dimensions of the rocking machines make it difficult to transport.lt is for this reason that there is a need for research in order to obtain new technical solutions.Studies have confirmed the costeffectiveness of plunger-type deep well pumps. The drive of such pumping units can be a cylindrical linear induction engine or a cylindrical linear valve engine.The use of this engine is possible with a known pulling force.It is calculated in this article. The calculation is made according to a simplified model of a cylindrical linear valve enginein a Cartesian coordinate system. This model is obtained by introducing some assumptions. The device and the principle of operation of a cylindrical linear valve engineare investigated.According to the calculated data, the dependences of the tractive effort and useful power on the current value of the inductor winding were built.Net power was determined in the range of ultralow frequencies from 1 to $7 \mathrm{~Hz}$. The obtained research results were analyzed and recommendations on the use of a cylindrical linear valve enginewere given.
\end{abstract}

Keywords: cylindrical linear AC electronic engine, pulling tool, ultralow frequency, permanent magnets, pole pitch, secondary element.

В настоящее время для добычи нефти из скважин в основном используются станки-качалки. Кроме неоспоримых преимуществ они имеют и серьезные недостатки. Именно по этой причине в качестве альтернативного решения могут быть цилиндрические линейные асинхронные электродвигатели (ЦЛАД) или цилиндрические линейные вентильные электродвигатели (ЦЛВД). Они уже достаточно широко применяются в электроприводах нефтедобывающей промышленности. Для добычи нефти из малодебитных скважин на них сейчас обычно устанавливают погружной бесштанговый электронасосный агрегат» (ПБЭНА), в состав которого входит ЦЛАД или ЦЛВД [1].

Преимущества цилиндрического линейного вентильного двигателя. Погружные плунжерные насосы с колонной насосных штанг, ис- 
пользуемые в настоящее время повсеместно для мало- и среднедебитных и глубоких скважин, не удовлетворяют в полной мере запросам потребителей. В связи с этим возникает необходимость разработки эффективного линейного электропривода (асинхронного или вентильного) для создания погружных плунжерных бесштанговых электронасосных агрегатов [2, 3].

Разработка и внедрение подобных устройств позволяют обеспечить ряд существенных преимуществ, обусловленных исключением колонны штанг и станка-качалки, что позволяет приблизить двигатель к насосному агрегату, а именно:

- снижение металлоемкости конструкции (при этом уменьшаются не только массовые, но и габаритные показатели), за счет этого уменьшаются затраты, связанные со строительными и монтажными работами [4];

- уменьшение затрат, связанных с производством подземных ремонтов;

- глубина опускания бесштангового электронасосного агрегата в скважину, который может достигать 3 км и больше [5, 6].

Устройство и принцип действия цилиндрического линейного вентильного двигателя. Состав ЦЛВД:

- неподвижный индуктор круглой формы предназначен для создания рабочего магнитного поля, движущегося поступательно;

- подвижная часть двигателя в виде штока, на котором крепятся постоянные магниты.

В этом двигателе магнитное поле движется поступательно по направлению оси ротора. На рис. 1 представлен продольный разрез ЦЛВД (слева - индуктор, справа - вторичный элемент - «шток»).

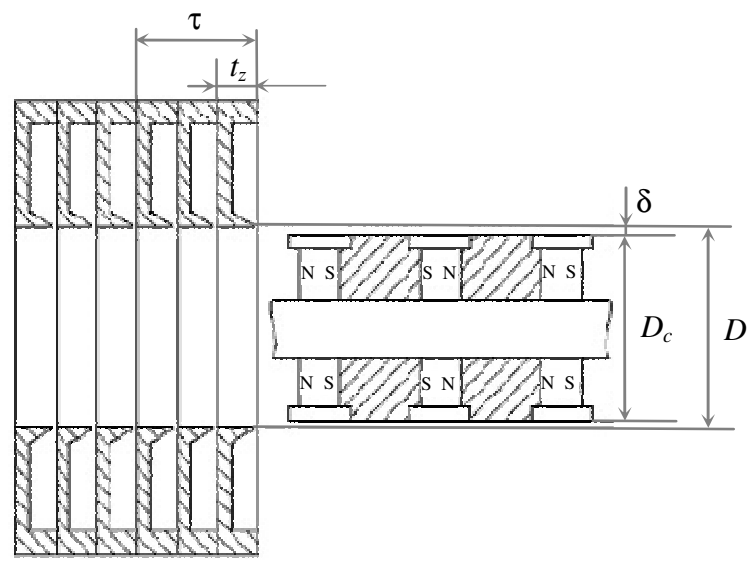

Рис. 1. Продольный разрез вторичного элемента и индуктора 
Катушки обмотки индуктора соединяются последовательно на протяжении всей его длины. Обмотка индуктора является трехфазной и снабжается электроэнергией от преобразователя частоты (ПЧ). Обмотка индуктора создает рабочее магнитное поле, поступательно движущееся по внутренней поверхности. Скорость движения и направление магнитного поля регулируются с помощью ПЧ [7, 8]. Диаметр вторичного элемента $D_{2}=55$. Воздушный зазор $\delta$ между индуктором и вторичным элементом составляет 1,5 мм и выдерживается равномерным по всей длине двигателя. Вторичный элемент (ротор) размещается внутри индуктора симметрично, и его горизонтальная ось проходит по середине штока. Концы штока вторичного элемента выходят за пределы индуктоpa c обеих сторон. Выступающие концы ротора закрепляются в подшипниках скольжения для уменьшения сил трения. Постоянные магниты вторичного элемента имеют следующие параметры: коэрцитивная сила $H_{0}=680$ кА/м, магнитная индукция $B_{Z}=1,1$ Тл [9-11].

Принцип действия электронасосного агрегата: поршень насоса совершает возвратно-поступательные движения благодаря непосредственной связи его со штоком электродвигателя типа ЦЛВД (или ЦЛАД). Электронасосный агрегат (двигатель и насос) полностью опускается в скважину на необходимую глубину. По кабельной линии на обмотку двигателя подается трехфазное напряжение от ПЧ, который находится в непосредственной близости от устья скважины на поверхности $[12,13]$.

Расчёт мощности и тягового усилия ЦЛВД. ЦЛВД погружного типа имеет модульную конструкцию, т.е. его полная рабочая конструкция состоит из отдельных модулей. Активная часть каждого модуля ЦЛВД имеет длину 980 мм. Для получения необходимого тягового усилия несколько модулей соединяют последовательно. Таким образом, определяется и длина реального ЦЛВД. Поскольку диаметр обсадной трубы скважины ограничивает возможный диаметр ЦЛВД $\left(D_{1}\right)$, то для получения необходимого тягового усилия следует увеличивать его длину. Именно по этой причине длина ЦЛВД на практике может составлять 8-10 м.

Шток плунжерного насоса соединяется с ротором ЦЛВД, и вместе они совершают возвратно-поступательное движение. Тяговое усилие при движении ротора обеспечивает рабочий ход вверх с усилием $F_{p}$ и обратный ход вниз с усилием $F_{0}$ при условии: $F_{0}<<F_{p}[14-16]$. 
Исследования проводились с использованием программного обеспечения Mathcad, с помощью которого были произведены все необходимые расчеты и построены графики различных зависимостей и характеристик. Основными характеристиками ЦЛВД для плунжерного насоса являются тяговое усилие $F$ и полезная мощность $P_{2}$ [17].

Исходные данные указаны в таблице.

\section{Исходные данные}

\begin{tabular}{|c|c|c|c|}
\hline $\begin{array}{c}\text { Условные } \\
\text { обозначения }\end{array}$ & $\begin{array}{c}\text { Единицы } \\
\text { измерения }\end{array}$ & Значения & Примечание \\
\hline$D_{p}$ & м & 0,055 & Диаметр ротора \\
\hline$I$ & А & 30 & Действующее значение тока обмотки индуктора \\
\hline$H_{0}$ & А/м & 680000 & Напряженность магнитного поля \\
\hline$B_{Z}$ & Тл & 1,1 & Магнитная индукция в зазоре \\
\hline$\tau$ & м & 0,03 & Полюсное деление \\
\hline$\delta$ & м & 0,0015 & Ширина немагнитного зазора \\
\hline$\beta$ & м & 0,015 & Ширина полюса \\
\hline$W_{k}$ & & 20 & Число витков в пазу \\
\hline$t_{Z}$ & м & 0,01 & Зубцовое деление индуктора \\
\hline$p$ & & 16 & Число пар полюсов \\
\hline$D_{M}$ & м & 0,047 & Внешний диаметр реального магнита ЦЛВД \\
\hline$d_{m}$ & м & 0,022 & Внутренний диаметр реального магнита ЦЛВД \\
\hline$h_{M}$ & м & 0,008 & Ширина реального магнита ЦЛВД \\
\hline$f$ & Гц & 1 & Частота сети \\
\hline$\mu_{0}$ & о.е. & $12,56 \cdot 10^{-7}$ & Магнитная проницаемость \\
\hline
\end{tabular}

Согласно закону Ампера тяговое усилие модуля ЦЛВД можно найти по формуле:

$$
F=\alpha \cdot \pi \cdot I_{\text {л }} \cdot B \cdot D \cdot l_{\text {мод }},
$$

где $I_{\text {л }}$ - линейная токовая нагрузка обмотки индуктора; $\alpha$ - коэффициент полюсного деления, $\alpha=\beta / \tau ; \beta$ - ширина полюса; $B$ - магнитная индукция в зазоре; $D$ - диаметр вторичного элемента между серединами воздушного зазора, $D=D_{2}+\delta ; l_{\text {мод }}$ - длина активной части одного модуля индуктора.

Линейная токовая нагрузка катушки обмотки индуктора определяется по формуле:

$$
I_{\text {л }}=\frac{W_{k} \cdot I}{t_{Z}},
$$


где $W_{k}$ - количество витков в катушке обмотки индуктора; $I$ - действующее значение тока обмотки индуктора; $t_{Z}$ - зубцовое деление индуктора.

Все величины, входящие в формулу (1) и участвующие в определения тягового усилия, заданы, исходя из геометрических размеров и токовой нагрузки обмотки (2). Исключением является магнитная индукция в зазоре, так как она при расчете по формуле (1) неизвестна.

Магнитная индукция в зазоре ЦЛВД создается постоянными магнитами, расположенными на немагнитном штоке вторичного элемента, и токами обмотки индуктора (реакция якоря) [18]. На базе идеализированной расчетной модели, изображенной на рис. 2, производится расчет магнитного поля в зазоре на протяжении полюсного деления.

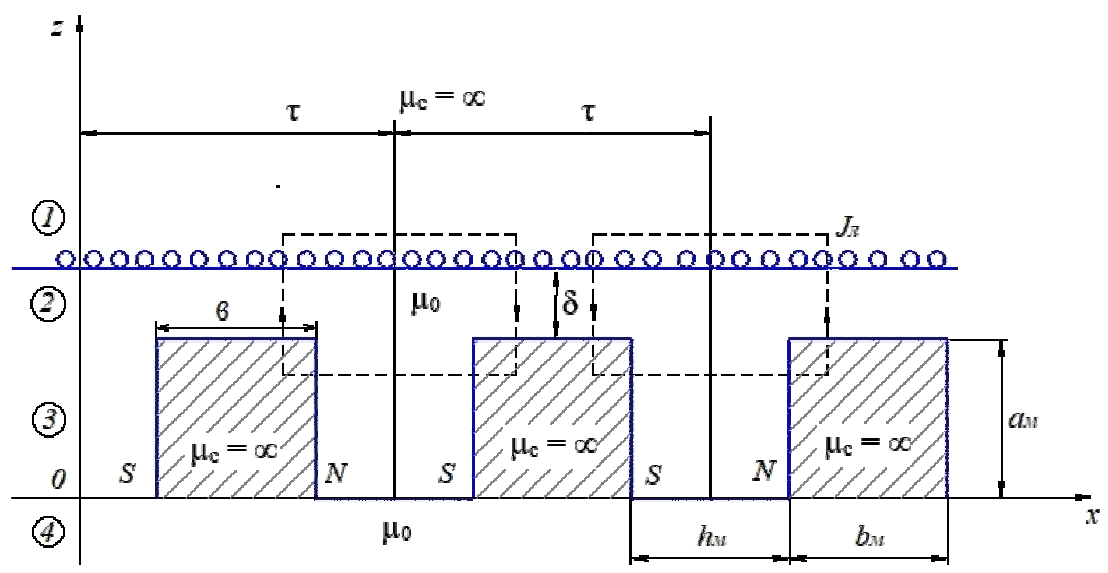

Рис. 2. Расчетная модель цилиндрического линейного вентильного двигателя

В основу расчетной модели положены следующие допущения:

1. Ферромагнитные сердечники индуктора с $\mu_{c}=\infty, \gamma_{c}=0$ по направлению оси $X$ имеют бесконечные размеры, а длина активной части двигателя $l_{\text {мод }}=2 \cdot p \cdot \tau$;

2. Ширина двигателя (зона 1) в направлении оси $Y$ бесконечно велика;

3. Сердечник индуктора не имеет пазов, а их влияние учитывается соответствующим увеличением зазора;

4. Магнитная проницаемость полюсов вторичного элемента бесконечно велика, а их ширина равна $\beta$; 
5. Магниты намагничены по направлению оси $X$, их магнитная проницаемость равна $\mu_{0}$, а ширина $h_{\mathrm{M}}$;

6. Магнитная проницаемость зазора в зоне 2 и в зоне 4 равна $\mu_{0}$;

7. Магнитная индукция в воздушном зазоре имеет только одну составляющую, и направлена она по оси $Z$.

Реальные геометрические размеры магнита представлены на рис. 3.

При переходе от цилиндрической системы координат к декартовой реальные геометрические размеры магнита также изменяется согласно рис. 4. В этом случае ширина магнита остается $h_{\mathrm{M}}$, а длина определяется пунктирной линией $l_{\text {ср }}$ на рис. 3:

$$
l_{\mathrm{cp}}=0,5\left(D_{\mathrm{M}}+d_{\mathrm{M}}\right) \pi .
$$

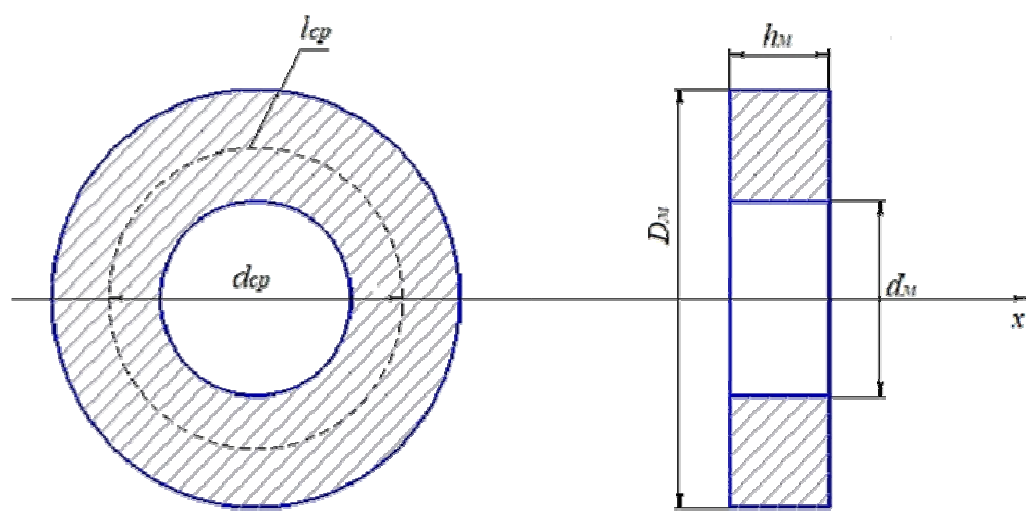

Рис. 3. Реальный магнит цилиндрического линейного вентильного двигателя

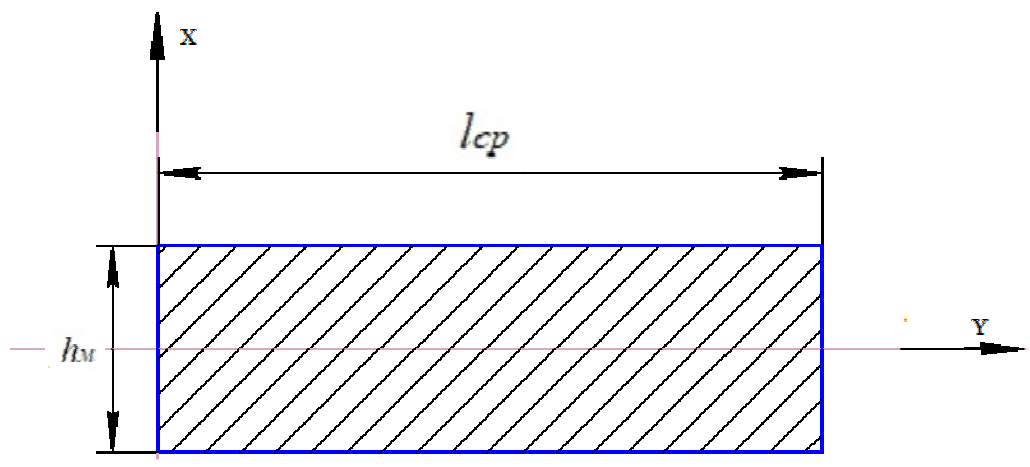

Рис. 4. Магнит цилиндрического линейного вентильного двигателя в декартовой системе координат 
Высота магнита по координате $Z$ в декартовой системе координат определяется по выражению:

$$
a_{\mathrm{M}}=0,5\left(D_{\mathrm{M}}+d_{\mathrm{M}}\right) .
$$

При принятых в расчетной модели допущениях, магнитное поле, возбуждаемое постоянным магнитом, замыкается по пути, который обозначен пунктирной линией на рис. 2. Таким образом, магнитный поток магнита два раза пересекает воздушный зазор и замыкается на половине двух соседних полюсов $[19,20]$.

Магнитное сопротивление в зазоре определяется по выражению:

$$
R_{\delta}=\frac{4 \cdot \delta}{\mu_{0} \cdot \beta \cdot l},
$$

где $l$ - длина воздушного зазора ЦЛВД, $l=\pi\left(D_{2}+\delta\right) ; D_{2}$ - диаметр вторичного элемента.

Магнитное сопротивление магнита на участке $h_{\mathrm{M}}$ :

$$
\begin{gathered}
R_{\mathrm{M}}=\frac{H_{0} \cdot h_{\mathrm{M}} \cdot 2}{B_{2}+S_{\mathrm{M}}}, \\
S_{\mathrm{M}}=l_{\mathrm{cp}} \cdot a_{\mathrm{M}}
\end{gathered}
$$

Магнитно-движущая сила магнита определяется согласно [7]:

$$
F_{\mathrm{M}}=H_{0} \cdot h_{\mathrm{M}} \cdot
$$

При принятых допущениях магнитный поток на половине полюса $\phi_{\delta}$ определяется на основе эквивалентной электрической принципиальной схемы замещения магнитной цепи, представленной на рис. 5 [21].

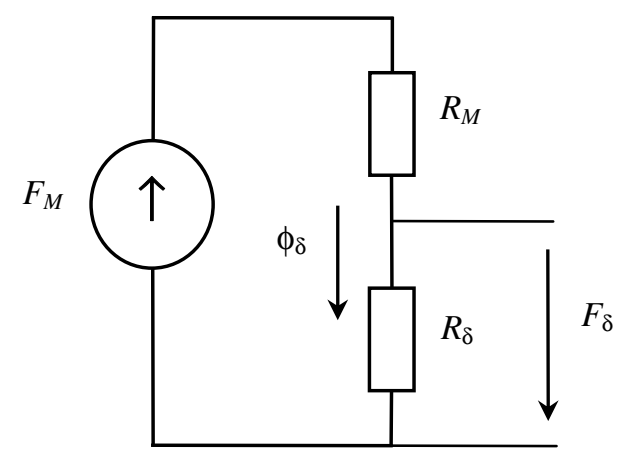

Рис. 5 Эквивалентная схема замещения магнитной цепи ЦЛВД 
На основании этой эквивалентной схемы замещения можно записать:

$$
\phi_{\delta}=\frac{F_{M}}{R_{M}+R_{\delta}}
$$

Индукция в зазоре ЦЛВД:

$$
B_{\text {ср }}=\frac{2 \cdot \phi_{\delta}}{S_{\text {пол }}},
$$

где $S_{\text {пол }}-$ площадь одного полюса, $S_{\text {пол }}=\beta \cdot l$.

Скорость холостого хода

$$
v_{0}=2 \cdot \tau \cdot f .
$$

Полезная мощность

$$
P_{2}=F_{\text {эм }} \cdot v .
$$

Проведя аналогичные расчеты и изменяя действующий ток обмотки индуктора $I$ в диапазоне от 5 до 35 А с шагом 5 А, были определены значения тягового усилия $F_{2}$ и установлена зависимость тягового усилия от действующего тока обмотки индуктора (рис. 6).

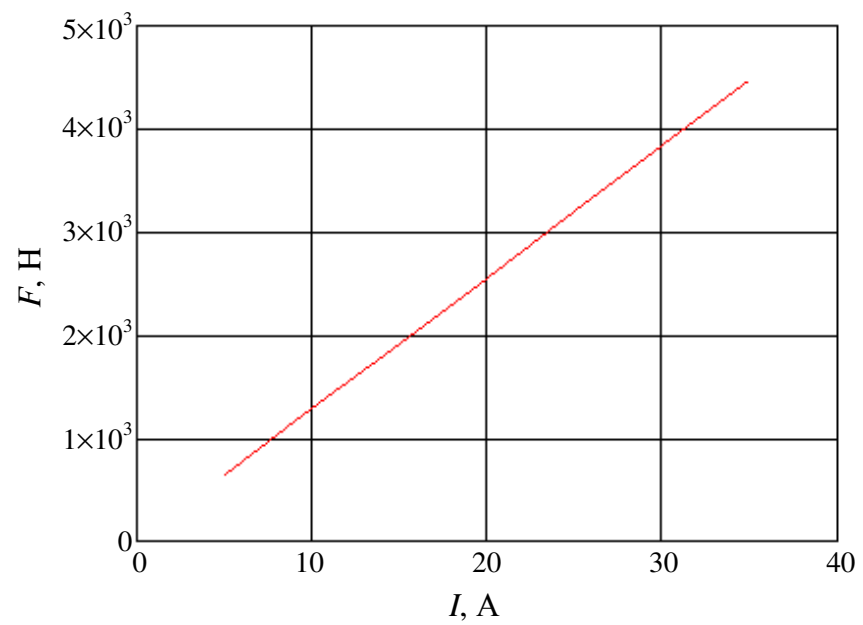

Рис. 6. Графическая зависимость тягового усилия от действующего тока обмотки индуктора: $F=f(I)$

Исследуя мощность цилиндрического линейного вентильного двигателя, были получены следующие характеристики двигателя в диапазоне сверхнизких частот: от 1 до 7 Гц, с шагом 1 Гц. 
В соответствии с полученными данными были построены графические зависимости изменения значения полезной мощности $P_{2}$ от значения действующего тока обмотки индуктора $I$ в диапазоне сверхнизких частот от 1 до 7 Гц (рис. 7).

При этом изменение частоты не повлияло на значение тягового усилия ЦЛВД, и графическая зависимость тягового усилия $F_{2}$ от действующего тока обмотки индуктора $I$ при разных частотах изменяться не будет, и будет иметь вид, как на рис. 6.

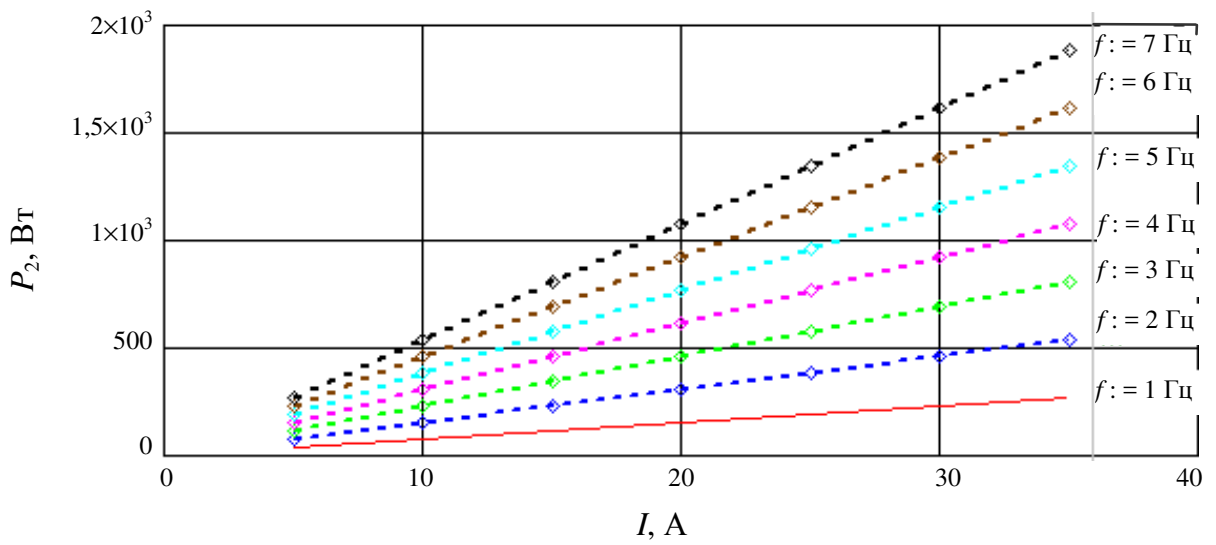

Рис. 7. Графические зависимости изменения значения мощности от значения действующего тока обмотки индуктора в диапазоне сверхнизких частот от 1 до 7 Гц

Выводы. Для мало- и среднедебитных скважин были рассмотрены альтернативные способы добычи нефти, которые отличаются от широко распространенных в настоящее время станков-качалок.

С помощью проведенных исследований и расчетов было подтверждено, что ЦЛВД с начальными данными, указанными в таблице, имеет достаточное тяговое усилие и мощность для того, чтобы работать в составе «погружного бесштангового электронасосного агрегата» для улучшения добычи нефти из малодебитных скважин [22].

Полученные результаты доказали актуальность и перспективность использования ЦЛВД в совокупности с плунжерным насосом, что позволило избежать ряд недостатков, присущих станкам-качалкам с колонной насосных штанг [23-25]. 


\section{Библиографический список}

1. Модернизация оборудования станков-качалок низкодебетных нефтяных скважин / Е.М. Огарков, А.Д. Коротаев, П.Н. Цылёв, А.М. Бурмакин // Научные исследования и инновации: науч.-техн. журнал. - Пермь: Изд-во Перм. гос. техн. ун-та, 2009. - № 4. - С. 59-65.

2. Окунеева Н.А. Разработка и исследование электропривода для нефтедобывающих насосов с погружным магнитоэлектрическим двигателем: дис. ... канд. техн. наук: 05.09.03 / Моск. энергет. ин-т. - М., 2008. - $204 \mathrm{c}$.

3. Кабиров М.М., Гафаров Ш.А. Скважинная добыча нефти. СПб.: Недра, 2010. - 416 с.

4. Скважинные насосныеустановки для добычи нефти / В.Н. Ивановский, В.И. Дарищев, А.А. Сабиров, В.С. Каштанов, С.С. Пекин. М.: Изд-во «Нефть и газ» РГУ нефти и газа им. И.М. Губкина, 2002. $-768 \mathrm{c}$.

5. Шулаков Н.В., Шутемов С.В. Перспективы использования цилиндрическоголинейного вентильного двигателя в качестве привода плунжерных нефтедобычных агрегатов // Фундаментальные исследования. - 2016. - № 12-4. - С. 795-799.

6. Любимов Э.В., Шулаков Н.В., Шутемов С.В. Обоснование применения цилиндрического линейного вентильного двигателя в нефтедобычных агрегатах // Успехи современного естествознания. - 2018. № 3. - С. 94-100.

7. Вольдек А.И. Индукционные магнитогидродинамические машины с жидкометаллическим рабочим телом. - Л.: Энергия, 1970. - 272 с.

8. Вольдек А.И. Электрические машины: учеб. для студ. втузов. 2-е изд., перераб. и доп. - М.: Энергия, 1974. - 840 с.

9. Ключников А.Т., Коротаев А.Д., С.В. Шутемов. Моделирование цилиндрического линейного вентильного двигателя // Электротехника. 2013. - № 11. - С. 14-16.

10. Богданов А.А. Погружные центробежные электронасосы для добычи нефти. - М.: Недра, 1986.

11. Ледовский А.Н. Электрические машины с высококоэрцитивными постоянными магнитами. - М.: Энергоатомиздат, 1985.

12. Шутемов С.В. Исследование использования цилиндрического вентильного электродвигателя для погружного бесштангового насоса // Фундаментальные исследования. - 2016. - № 12-4. - С. 800-805. 
13. Цилиндрический линейный вентильный электродвигатель для погружного бесштангового насоса / А.Т. Ключников, А.Д. Коротаев, Н.В. Шулаков, С.В. Шутемов // Автоматизация в электроэнергетике и электротехнике. - 2015. - Т. 1. - С. 158-162.

14. Shulakov N.V., Shutemov S.V. A method for calculating the electromagnetic processes in a cylindrical linear electronic motor // Russian Electrical Engineering. - 2014. - Vol. 85, № 11. - P. 663-667. (Scopus).

15. Shulakov N.V., Ogarkov E.M., Burmakin A.M. Equivalent circuit of linear induction motor // Russian Electrical Engineering. - 2010. - Vol. 81. № 6. - P. 282-286. (Scopus).

16. Klyuchnikov A.T., Korotaev A.D., Shutemov S.V. Modeling of a Cylindrical Linear AC Electronic Motor // Russian Electrical Engineering. 2013. - Vol. 84, № 11. - P. 606-609. (Scopus).

17. Мирзин А.М., Коротаев А.Д., Шутемов С.В. Усилие тяжения цилиндрического линейноговентильногодвигателя с постоянными магнитами между статором и вторичным элементом // Современные проблемы науки и образования. - 2013. - № 6.

18. Огарков Е.М., Тиунов В.В. Продольный краевой эффект линейных индукционных двигателей с учётом характера распределения поля в концевых зонах // Специальные системы электропривода: сб. науч. тр. / Перм. политехн. ин-т. - Пермь, 1973. - № 133. - С. 29-36.

19. Метод расчета электромагнитных процессов в цилиндрическом линейном вентильном двигателе / А.Т. Ключников, А.Д. Коротаев, Н.В. Шулаков, С.В. Шутемов // Автоматизация в электроэнергетике и электротехнике. - 2015. - Т. 1. - С. 163-169.

20. Бинс К., Лауренсон П. Анализ и расчёт электрических и магнитных полей. - М.: Энергия, 1970. - 376 с.

21. Чирков Д.А., Коротаев А.Д., Ключников А.Т. Расчёт основных параметров цилиндрического линейного вентильного двигателя по схеме замещения // Автоматизация в электроэнергетике и электротехнике. 2016. - T. 1. - C. 144-149.

22. Исследование эффекта тяжения цилиндрического линейного вентильного электродвигателя / А.Д. Петрушин, А.В. Шевкунова, Н.В. Шулаков, С.В. Шутемов // Вестник Пермского национального исследовательского политехнического университета. Электротехника, информационные технологии, системы управления. - 2018. № 28. - C. 62-75. 
23. Любимов Э.В., Шулаков Н.В., Шутемов С.В. Обоснование применения ЦЛВД в составе ПБНА // Актуальные проблемы электромеханики и электротехнологий: сб. науч. тр. - 2017. - С. 95-98.

24. Мищенко И.Т. Скважинная добыча нефти: учеб. пособие. - М.: Изд-во «Нефть и газ» РГУ нефти и газа им. И.М. Губкина. $-2003 .-816$ с.

25. Шулаков Н.В., Шутемов С.В. Метод расчёта электромагнитных процессов в цилиндрическом линейном вентильном двигателе // Электротехника. - 2014. - № 11. - С. 18-22.

\section{References}

1. Ogarkov E.M., Korotaev A.D., Tsylev P.N., Burmakin A.M. Modernizatsiia oborudovaniia stankov-kachalok nizkodebetnykh neftianykh skvazhin [Modernization of equipment of pumping units of low-income oil wells]. Nauchnye issledovaniia i innovatsii: nauchnotekhnicheskii zhurnal. Perm': Permskii gosudarstvennyi tekhnicheskii universitet, 2009, no., 4, pp. 59-65.

2. Okuneeva N.A. Razrabotka i issledovanie elektroprivoda dlia neftedobyvaiushchikh nasosov $\mathrm{s}$ pogruzhnym magnitoelektricheskim dvigatelem: Elektrotekhnicheskie kompleksy i sistemy [Development and research of an electric drive for oil-producing pumps with a submersible magnetoelectric engine]. Ph.D. thesis. Moscow: Moskovskii energeticheskii institut, 2008. 204 p.

3. Kabirov M.M., Gafarov Sh.A. Skvazhinnaia dobycha nefti [Downhole oil production]. Saint Petersburg: Nedra, 2010. 416 p.

4. Ivanovskii V.N., Darishchev V.I., Sabirov A.A., Kashtanov V.S., Pekin S.S. Skvazhinnye nasosnyeustanovki dlia dobychi nefti [Downhole pumping units for oil production]. Moscow: "Neft' i gaz" Rossiiskii gosudarstvennyi universitet nefti i gaza imeni I. M. Gubkina, 2002. 768 p.

5. Shulakov N.V., Shutemov S.V. Perspektivy ispol'zovaniia tsilindricheskogolineinogo ventil'nogo dvigatelia $\mathrm{v}$ kachestve privoda plunzhernykh neftedobychnykh agregatov [Prospects for the use of a cylindrical linear valve motor as a drive for plunger oil-producing units]. Fundamental'nye issledovaniia, 2016, no. 12-4, pp. 795-799.

6. Liubimov E.V., Shulakov N.V., Shutemov S.V. Obosnovanie primeneniia tsilindricheskogo lineinogo ventil'nogo dvigatelia $\mathrm{v}$ neftedobychnykh agregatakh [Substantiation of the use of a cylindrical linear valve motor in oil production units]. Uspekhi sovremennogo estestvoznaniia, 2018, no. 3, pp. 94-100. 
7. Vol'dek A.I. Induktsionnye magnitogidrodinamicheskie mashiny s zhidkometallicheskim rabochim telom [Inductive magnetohydrodynamic machines with liquid metal working fluid]. Leningrad: Energiia, 1970. 272 p.

8. Vol'dek A.I. Elektricheskie mashiny [Electric cars]. 2nd ed. Moscow: Energiia, 1974. 840 p.

9. Kliuchnikov A.T., Korotaev A.D., S.V. Shutemov. Modelirovanie tsilindricheskogo lineinogo ventil'nogo dvigatelia [Modeling a cylindrical linear valve motor]. Elektrotekhnika, 2013, no. 11, pp. 14-16.

10. Bogdanov A.A. Pogruzhnye tsentrobezhnye elektronasosy dlia dobychi nefti [Submersible centrifugal electric pumps for oil production]. Moscow: Nedra, 1986.

11. Ledovskii A.N. Elektricheskie mashiny s vysokokoertsitivnymi postoiannymi magnitami [Electric machines with highly coercive permanent magnets]. Moscow: Energoatomizdat, 1985.

12. Shutemov S.V. Issledovanie ispol'zovaniia tsilindricheskogo ventil'nogo elektrodvigatelia dlia pogruzhnogo besshtangovogo nasosa [The study of the use of a cylindrical valve motor for a submersible rodless pump]. Fundamental'nye issledovaniia, 2016, no. 12-4, pp. 800-805.

13. Kliuchnikov A.T., Korotaev A.D., Shulakov N.V., Shutemov S.V. Tsilindricheskii lineinyi ventil'nyi elektrodvigatel' dlia pogruzhnogo besshtangovogo nasosa [A cylindrical linear valve electric motor for a submersible rodless pump]. Avtomatizatsiia v elektroenergetike i elektrotekhnike, 2015, vol. 1, pp. 158-162.

14. Shulakov N.V., Shutemov S.V. A method for calculating the electromagnetic processes in a cylindrical linear electronic motor. Russian Electrical Engineering, 2014, vol. 85, no. 11, pp. 663-667. (Scopus).

15. Shulakov N.V., Ogarkov E.M., Burmakin A.M. Equivalent circuit of linear induction motor. Russian Electrical Engineering, 2010, vol. 81, no. 6, pp. 282-286. (Scopus).

16. Klyuchnikov A.T., Korotaev A.D., Shutemov S.V. Modeling of a Cylindrical Linear AC Electronic Motor. Russian Electrical Engineering, 2013, vol. 84, no. 11, pp. 606-609. (Scopus).

17. Mirzin A.M., Korotaev A.D., Shutemov S.V. Usilie tiazheniia tsilindricheskogo lineinogo ventil'nogod vigatelia s postoiannymi magnitami mezhdu statorom i vtorichnym elementom [The tensile force of a cylindrical linear valve motor with permanent magnets between the stator and the secondary element]. Sovremennye problemy nauki i obrazovaniia, 2013, no. 6. 
18. Ogarkov E.M., Tiunov V.V. Prodol'nyi kraevoi effekt lineinykh induktsionnykh dvigatelei $\mathrm{s}$ uchetom kharaktera raspredeleniia polia $\mathrm{v}$ kontsevykh zonakh [Longitudinal edge effect of linear induction motors, taking into account the nature of the field distribution in the end zones]. Spetsial'nye sistemy elektroprivoda. Sbornik nauchnykh trudov. Perm': Permskii politekhnicheskii institut, 1973, no. 133, pp. 29-36.

19. Kliuchnikov A.T., Korotaev A.D., Shulakov N.V., Shutemov S.V. Metod rascheta elektromagnitnykh protsessov $\mathrm{v}$ tsilindricheskom lineinom ventil'nom dvigatele [Method for calculating electromagnetic processes in a cylindrical linear valve motor]. Avtomatizatsiia $v$ elektroenergetike $i$ elektrotekhnike, 2015, vol. 1, pp. 163-169.

20. Bins K., Laurenson P. Analiz i raschet elektricheskikh i magnitnykh polei [Analysis and calculation of electric and magnetic fields]. Moscow: Energiia, 1970. 376 p.

21. Chirkov D.A., Korotaev A.D., Kliuchnikov A.T. Raschet osnovnykh parametrov tsilindricheskogo lineinogoventil'nogo dvigatelia po skheme zameshcheniia [Calculation of the main parameters of a cylindrical linear valve motor according to the equivalent circuit]. Avtomatizatsiia $v$ elektroenergetike i elektrotekhnike, 2016, vol. 1, pp. 144-149.

22. Petrushin A.D., Shevkunova A.V., Shulakov N.V., Shutemov S.V. Issledovanie effekta tiazheniia tsilindricheskogo lineinogo ventil'nogo elektrodvigatelia [Investigation of the traction effect of a cylindrical linear valve electric motor]. Vestnik Permskogo natsional'nogo issledovatel'skogo politekhnicheskogo universiteta. Elektrotekhnika, informatsionnye tekhnologii, sistemy upravleniia, 2018, no. 28, pp. 62-75.

23. Liubimov E.V., Shulakov N.V., Shutemov S.V. Obosnovanie primeneniia TsLVD $\mathrm{v}$ sostave PBNA [Substantiation of application of TsLVD in structure PBNA]. Aktual'nye problemy elektromekhaniki $i$ elektrotekhnologii. Sbornik nauchnykh trudov, 2017, pp. 95-98.

24. Mishchenko I.T. Skvazhinnaia dobycha nefti [Oil well production]. Moscow: "Neft' i gaz" Rossiiskii gosudarstvennyi universitet nefti i gaza imeni I. M. Gubkina, 2003. 816 p.

25. Shulakov N.V., Shutemov S.V. Metod rascheta elektromagnitnykh protsessov $\mathrm{v}$ tsilindricheskom lineinom ventil'nom dvigatele [The method of calculation of electromagnetic processes in a cylindrical linear valve motor]. Elektrotekhnika, 2014, no. 11, pp. 18-22. 


\section{Сведения об авторах}

Шапошников Владислав Валерьевич (Пермь, Россия) - магистрант Пермского национального исследовательского политехнического университета (614990, Пермь, Комсомольский пр. 29, e-mail: vladislav96gg@gmail.com).

Токарев Роман Олегович (Пермь, Россия) - магистрант Пермского национального исследовательского политехнического университета (614990, Пермь, Комсомольский пр. 29, e-mail: ju11071996@yandex.ru).

Коротаев Александр Дмитриевич (Пермь, Россия) - кандидат технических наук, доцент кафедры «Электротехника и электромеханика» Пермского национального исследовательского политехнического университета (614990, Пермь, Комсомольский пр. 29, e-mail: ceapb@mail.ru).

Чабанов Евгений Александрович (Пермь, Россия) - кандидат технических наук, доцент кафедры «Электротехника и электромеханика» Пермского национального исследовательского политехнического университета (614990, Пермь, Комсомольский пр. 29), доцент кафедры «Технические дисциплины» Волжского государственного университета водного транспорта (Пермский филиал) (614060, Пермь, Гагарина бульвар, 33), e-mail: ceapb@mail.ru).

\section{About the authors}

Shaposhnikov Vladislav Valeryevich (Perm, Russian Federation) is a Student Perm National Research Polytechnic University (614990, Perm, 29, Komsomolsky pr. e-mail: vladislav96gg@gmail.com).

Tokarev Roman Olegovich (Perm, Russian Federation) is a Student Perm National Research Polytechnic University (614990, Perm, 29, Komsomolsky pr., e-mail: ju11071996@yandex.ru).

Korotaev Aleksandr Dmitrievich (Perm, Russian Federation) is a Ph.D in Technical Sciences, Associate Professor of Department of Electrical Engineering and Electromechanics of Perm National Research Polytechnic University (614990, Perm, 29, Komsomolsky pr., e-mail: ceapb@mail.ru).

Chabanov Evgenii Aleksandrovich (Perm, Russian Federation) is a $\mathrm{Ph} . \mathrm{D}$ in Technical Sciences, Associate Professor of Department of Electrical Engineering and Electromechanics of Perm National Research Polytechnic University (614990, Perm, 29, Komsomolsky pr.), Associate Professor of Department of Technical Disciplines of Volga State University of Water Transport (Perm branch) (614060, Perm, 33, Gagarina bulvar, e-mail: ceapb@mail.ru).

Получено 30.10.2019 